\title{
Phase I-II study of lenalidomide and alemtuzumab in refractory chronic lymphocytic leukemia (CLL): effects on $T$ cells and immune checkpoints
}

\author{
Maria Winqvist ${ }^{1,2}$ - Fariba Mozaffari ${ }^{2}$ - Marzia Palma ${ }^{1,2}$ - Sandra Eketorp Sylvan ${ }^{2}$. \\ Lotta Hansson $^{1,2} \cdot$ Håkan Mellstedt ${ }^{2} \cdot$ Anders Österborg $^{1,2} \cdot$ Jeanette Lundin $^{1,2}$
}

Received: 29 June 2016 / Accepted: 27 October 2016 / Published online: 4 November 2016

(C) The Author(s) 2016. This article is published with open access at Springerlink.com

\begin{abstract}
This phase I-II study explored safety, immunomodulatory and clinical effects of lenalidomide (weeks 1-16) and alemtuzumab (weeks 5-16) in 23 patients with refractory chronic lymphocytic leukemia. Most patients had Rai stage III/IV disease and were heavily pretreated (median 4 prior therapies), and $61 \%$ had $\operatorname{del}(17 \mathrm{p}) / \mathrm{del}(11 \mathrm{q})$. Eleven of 19 evaluable patients (58\%) responded, with a median response duration of 12 months $(1-29+)$; time to progression was short in non-responders. Lenalidomide had a narrow therapeutic dose range, $2.5 \mathrm{mg} /$ day was not efficient, and maximum tolerated dose was $5 \mathrm{mg} /$ day. Grade 3-4 neutropenia and thrombocytopenia occurred in 84 and 55\%, 30\% had febrile neutropenia, and CMVreactivation requiring valganciclovir occurred in $30 \%$ of patients. The frequency of proliferating $\left(\mathrm{Ki}_{6} 7^{+}\right) \mathrm{CD} 8^{+} \mathrm{T}$ cells was increased at week 4 , with further increase in both the $\mathrm{CD}^{+}$and $\mathrm{CD} 8^{+}$subsets $(p<0.01$ and $<0.05)$, which
\end{abstract}

Presented in part at the Annual Meeting of the American Society of Hematology (ASH), Orlando, FL, USA, Dec 5-8, 2015.

Anders Österborg and Jeanette Lundin contributed equally to this work.

Electronic supplementary material The online version of this article (doi:10.1007/s00262-016-1922-6) contains supplementary material, which is available to authorized users.

Maria Winqvist

maria.winqvist@karolinska.se

1 Department of Hematology, Karolinska University Hospital Solna, 17176 Stockholm, Sweden

2 Department of Oncology-Pathology, Karolinska Institutet, Stockholm, Sweden was accompanied by significant upregulation of HLA-DR after addition of alemtuzumab. Antigen-experienced cells increased at week 4 as the frequency of effector memory cells increased in the $\mathrm{CD}^{+}$subset $(p<0.003)$, while effector cells decreased in both the $\mathrm{CD}^{+}$and $\mathrm{CD}^{+}$subsets $(p<0.0001$ and $p<0.01)$. The Th1/Th2 balance was unchanged at week 4 but shifted toward a Th2 profile after combination therapy. At end of treatment, the frequency of Th17 and regulatory $\mathrm{T}$ cells was reduced $(p<0.01)$, naïve $\mathrm{T}$ cells decreased, and effector memory $\mathrm{T}$ cells increased $(p<0.05$ and $p<0.01)$. Granzyme $\mathrm{B}^{+} \mathrm{T}$ cells increased at 30 -week follow-up $(p<0.05)$. PD-1 expression was unaffected. In conclusion, low-dose lenalidomide and alemtuzumab induced major perturbations of $\mathrm{T}$ cells, including increased proliferative activity and cytotoxic potential.

Keywords Chronic lymphocytic leukemia .

Lenalidomide $\cdot$ Alemtuzumab $\cdot \mathrm{T}$ cells $\cdot$ Immune checkpoints

$\begin{array}{ll}\text { Abbreviations } \\ \text { CCR } & \text { C-C motif chemokine receptor } \\ \text { CLL } & \text { Chronic lymphocytic leukemia } \\ \text { CXCR } & \text { C-X-C motif chemokine receptor } \\ \text { ECOG } & \text { Eastern Cooperative Oncology Group } \\ \text { HLA-DR } & \text { Human leukocyte antigen-antigen D related } \\ \text { IgHV } & \text { Ig heavy chain variable } \\ \text { MTD } & \text { Maximum tolerated dose } \\ \text { NKT cell } & \text { Natural killer T cell } \\ \text { ORR } & \text { Overall response rate } \\ \text { TFR } & \text { Tumor flare reaction } \\ \text { Th1 cell } & \text { Type 1 T helper cell } \\ \text { Th2 cell } & \text { Type 2 T helper cell } \\ \text { Th17 cell } & \text { Type 17 T helper cell } \\ \mathrm{T}_{\text {reg }} & \text { Regulatory T cell }\end{array}$




\section{Introduction}

Chronic lymphocytic leukemia (CLL) is associated with impaired immune functions resulting in increased risk of infections and secondary tumors. Patients often have hypogammaglobulinemia and abnormalities in $\mathrm{T}$ and $\mathrm{NK}$ cells. T cell dysfunctions are due to several factors, such as defective immunological synapse formation [1], impaired cell cytotoxicity [2] and imbalance in cell subsets [3, 4].

Lenalidomide is an immunomodulatory drug which has shown anti-tumor activity in patients with relapsed and/or refractory CLL, achieving an overall response rate (ORR) of 32-47\% [5-7]. The most prominent side effects of lenalidomide in CLL are neutropenia and tumor flare reaction (TFR), with a dose-dependent risk of tumor lysis syndrome [6].

The mechanisms of action for lenalidomide in CLL are not entirely understood, but might include a direct tumor cell killing effect, immune modulation and alteration of the tumor microenvironment. Altered cytokine levels, upregulation of co-stimulatory molecules on CLL cells, normalized balance of $\mathrm{T}$ cell subsets and improved NK and $\mathrm{T}$ cell function have been reported in CLL patients treated with lenalidomide (reviewed in [8]). Moreover, immunomodulatory drugs reduced the number of regulatory $\mathrm{T}$ cells $\left(\mathrm{T}_{\text {regs }}\right)[9,10]$, which are usually increased in patients with advanced-stage CLL $[4,9,11]$ and expanded pro-inflammatory type $17 \mathrm{~T}$ helper (Th17) cells [10]. Furthermore, immunomodulatory drugs induced $\mathrm{T}$ cell activation, proliferation and cytokine production in vitro without mitogenic activity $[12,13]$, but by a co-stimulatory effect $[13,14]$. In vitro studies have also shown that lenalidomide may improve $\mathrm{T}$ cell functions by repairing the defective immunological synapse formation with CLL cells [15]. In vivo, lenalidomide treatment increased the number of $\mathrm{CD} 8^{+} \mathrm{CD} 9^{+}$cells as well as IFN- $\gamma$-producing $\mathrm{CD} 8^{+}$cells, indicating an enhanced cytotoxic activity $[10,16]$. Lenalidomide also induced production of IL-2 and IFN- $\gamma$ in vivo, mediating a shift toward a type $1 \mathrm{~T}$ helper (Th1) cells profile [17].

$\mathrm{T}$ cell activation through the TCR is regulated by a number of co-stimulatory and inhibitory signals, including immune checkpoint receptors. This ultimately controls $\mathrm{T}$ cell activation in lymph nodes and effector responses in peripheral tissues. In particular, the immune checkpoint receptor PD-1 is induced on activated T cells, and once bound to the ligands, PD-L1 or PD-L2, expressed on tumor cells or cells in the tumor microenvironment, reduces TCR signaling [18].

$\mathrm{T}$ cells in CLL patients displayed a high PD-1 expression $[2,4,19]$, and chemotherapy seemed to increase the proportion of $\mathrm{CD} 4^{+} \mathrm{PD}-1^{+}$. This increase could be reversed by lenalidomide treatment [20]. Regarding the expression of the ligand PD-L1 on CLL cells, results are conflicting $[4,15,19]$. CTLA-4 is another immune checkpoint molecule transiently expressed on activated $\mathrm{T}$ cells [21] inhibiting $\mathrm{T}$ cell activation. It has been reported that lenalidomide could overcome the inhibitory effect of CTLA- 4 on T cell responses against the Epstein-Barr virus in vitro [14]. The expression profile of CTLA- 4 on T cells from CLL patients has shown varying results $[2,4,22]$.

Alemtuzumab is a humanized CD52 mAb that induced a response rate of $30-40 \%$ in relapsed/refractory CLL patients [23, 24]. Even though no longer approved for CLL but re-launched in multiple sclerosis, it is available through a free access program for CLL and other patients with an unmet need. Antibody-dependent cellular cytotoxicity, mainly induced by NK cells, is supposed to be an important effector function of alemtuzumab, but also depleting immune cells leading to an increased risk of opportunistic and other infections.

The rationale for combining lenalidomide with alemtuzumab in the present trial was based on the assumption that lenalidomide might potentiate the antitumor activity of alemtuzumab by stimulating NK cell-mediated antibodydependent cellular cytotoxicity and activate $\mathrm{T}$ cells to counteract the alemtuzumab-induced negative effect on $\mathrm{T}$ cells. Moreover, a synergistic effect might be expected, as the two drugs may have preferential effects in different disease compartments, i.e., alemtuzumab mostly on bone marrow and peripheral blood and lenalidomide mainly on lymph nodes, even though late responses on lenalidomide may occur in the bone marrow.

Results of a phase I study, in which 12 refractory CLL patients were included, have previously been reported [25]. In the present report, the complete analysis of totally 23 patients is described, with a focus on analysis of changes in $\mathrm{T}$ cell subsets, including immune checkpoints as well as cell activation, proliferation and cytotoxic markers.

\section{Materials and methods}

\section{Study population and eligibility criteria}

The study was conducted according to the Declaration of Helsinki. Informed consent was obtained from all individual participants included in the study. The study was registered at clinical trials.gov and was approved by the Swedish Medical Products Agency (EudraCT number 2007-00743420 ) and the regional ethics committee. Patients with chemotherapy-refractory CLL or judged ineligible for chemotherapy due to, for example, del(17p)/TP53 mutation or severe cytopenia were included in the study. The following criteria should be fulfilled as well: neutrophils $\geq 0.5 \times 10^{9} / \mathrm{L}$, platelets $\geq 25 \times 10^{9} / \mathrm{L}$, creatinine $\leq 177 \mu \mathrm{mol} / \mathrm{L}$, total bilirubin 
$\leq 26 \mu \mathrm{mol} / \mathrm{L}$ and Eastern Cooperative Oncology Group

(ECOG) performance status $\leq 2$.

\section{Treatment schedule}

Lenalidomide was given continuously as a single agent for weeks $1-4$ at a starting dose of $2.5 \mathrm{mg} /$ day in patients 1-6 and $5 \mathrm{mg} /$ day in patients 7-23 [25]. Alemtuzumab was added at week 5 (30 $\mathrm{mg}$ s.c. three times a week), and lenalidomide was then escalated stepwise (5-10-15 mg/day) depending on tolerability. Maximum treatment period was 16 weeks of lenalidomide and 12 weeks of alemtuzumab.

Prophylaxis for tumor lysis syndrome and TFR was provided by proper hydration, allopurinol given 3 days before start of lenalidomide, as well as $10 \mathrm{mg}$ of prednisone/day during the first week of treatment and at dose escalations. All patients received infection prophylaxis with cotrimoxazole, valaciclovir and G-CSF (300 $\mu$ g s.c. three times a week to normal granulocyte count). CMV monitoring was not performed, although CMV-PCR test was carried out in case of unexplained fever.

\section{Assessments}

Response evaluation was based on the 2008 International Workshop on Chronic Lymphocytic Leukemia (iwCLL) criteria [26]. Patients were evaluated with computed tomography scan at the end of treatment as well as bone marrow biopsies at week 12 and at the end of treatment. Treatment toxicity was evaluated using National Cancer Institute (NCI) Common Terminology Criteria for Adverse Events v3.0 except for anemia, thrombocytopenia and neutropenia which were graded according to the grading scale for hematological toxicity in CLL studies [26]. Maximum tolerated dose (MTD) was defined as the dose that caused dose-limiting toxicity in less than one-third of the patients.

\section{Flow cytometric analysis of whole blood lymphocytes}

After lysis of red blood cells, cells were washed, resuspended in BD FACSFlow (BD Biosciences, San Diego, CA, USA) and stained according to the manufacturer's recommendation using fluorochrome-coupled antibodies for CD19, CD3, CD4, CD8, CD16, CD56, CD52, CD45RA, human leukocyte antigen-antigen D related (HLA-DR) and C-C motif chemokine receptor (CCR) 7 (Supplementary Table 1). After incubation and washing, cells were resuspended in FACSFlow and analyzed by flow cytometry using a FACSCanto II flow cytometer and analyzed by FACSDiva version 6.1.3 (BD Biosciences) or Infinicyt (Cytognos S.L., Salamanca, Spain).

\section{Flow cytometric analysis of PBMC}

PBMC were isolated from heparinized blood by density gradient centrifugation on a Ficoll-Hypaque (GE Healthcare, Uppsala, Sweden), washed twice with Dulbecco's phosphate-buffered saline $(0.9 \%)$ (Gibco, Life Technologies, Carlsbad, CA, USA). Cells were freshly used or stored in liquid nitrogen until use.

PBMC were then washed with CSB (BioLegend, San Diego, CA, USA) and stained for PD-1, CTLA-4, PD-L1, CCR6, C-X-C motif chemokine receptor (CXCR) 3, $\mathrm{CD} 25$, human leukocyte antigen-antigen D related (HLADR) (Supplementary Table 1) and the appropriate isotype controls. After incubation for surface staining and washing, cells were resuspended in CSB and flow cytometric analysis was done by FACSCanto II flow cytometer (BD Biosciences).

For intracellular staining, cells were resuspended in fixation/permeabilization buffer, incubated for $30 \mathrm{~min}$ at $4{ }^{\circ} \mathrm{C}$ and washed with permeabilization buffer (eBioscience). Antibodies (FOXp3, granzyme B, perforin, Ki67) were added to the resuspended cells and incubated for $30 \mathrm{~min}$ at room temperature. Excess of antibodies was removed by washing twice with permeabilization buffer. The cells were then resuspended in CSB and analyzed by flow cytometry using a FACSCanto II flow cytometer and analyzed by the FACSDiva version 6.1.3 (BD Biosciences) or the FlowJo version 8.8.2 (TreeStar, Ashland, OR, USA) softwares.

\section{Statistical methods}

Statistical analyses were performed using GraphPad Prism 6.0 and SPSS 23.0. Comparison of marker expression at different time points was done with the Wilcoxon signedrank test for related samples. All tests were two-sided and $p<0.05$ was considered significant. Survival analysis was done with the Kaplan-Meier method.

\section{Results}

\section{Patients}

Clinical characteristics of the patients are shown in Table 1. Median age was 69 years (range 61-85); 70\% had Rai stage III/IV, $48 \%$ bulky disease (lymphadenopathy $>5 \mathrm{~cm}$ ), $61 \% 17 \mathrm{p}$ and/or $11 \mathrm{q}$ deletion and $73 \%$ an unmutated $\mathrm{Ig}$ heavy chain variable (IgHV) gene. Patients were heavily pretreated having received a median of 4 prior therapies (range 1-7). Three patients had previous allo-SCT. 
Table 1 Patient characteristics $(n=23)$

\begin{tabular}{|c|c|c|}
\hline & Median (range) & $\%$ \\
\hline Age (years) & $69(61-85)$ & \\
\hline \multicolumn{3}{|l|}{ Gender } \\
\hline Male & & 61 \\
\hline Female & & 39 \\
\hline Number of previous regimens & $4(1-7)$ & \\
\hline \multicolumn{3}{|l|}{ ECOG } \\
\hline 0 & & 43 \\
\hline 1 & & 48 \\
\hline 2 & & 9 \\
\hline \multicolumn{3}{|l|}{ Rai stage } \\
\hline I & & 26 \\
\hline II & & 4 \\
\hline III & & 26 \\
\hline IV & & 44 \\
\hline \multicolumn{3}{|l|}{ Cytogenetic abnormality } \\
\hline $17 \mathrm{p}$ - or $T P 53$ mutation & & 43 \\
\hline $11 q-$ & & 30 \\
\hline $13 q-$ & & 52 \\
\hline $12+$ & & 13 \\
\hline Normal & & 17 \\
\hline Lymph nodes $>5 \mathrm{~cm}$ & & 48 \\
\hline Unmutated IgHV gene & & 73 \\
\hline Refractory to fludarabine or bendamustine & & 56 \\
\hline
\end{tabular}

\section{Dose and MTD}

The first six patients received a starting dose of $2.5 \mathrm{mg}$ lenalidomide/day. Four of these patients progressed early, and the dose was considered ineffective in advanced-phase progressive CLL [25]. After an amendment, the subsequent 17 patients received a starting dose of $5 \mathrm{mg} /$ day. Median length of lenalidomide therapy was 12 weeks (range 0-16) and for alemtuzumab 10 weeks (range 0-12). Eleven patients (48\%) completed all 16 weeks of lenalidomide and the 12 weeks of alemtuzumab therapy. MTD of lenalidomide, in combination with alemtuzumab, was $5 \mathrm{mg} / \mathrm{day}$. Only two patients tolerated a lenalidomide dose of $10 \mathrm{mg} /$ day for more than 4 weeks, and no patient reached a dose of $15 \mathrm{mg} /$ day. The most common dose-limiting toxicity was grade $3-4$ neutropenia ( $15 / 17$ of patients).

\section{Efficacy}

Four patients discontinued lenalidomide within 8 weeks due to causes other than disease progression. In one patient, the drug was withdrawn after two doses due to rapidly deteriorating general condition. Three patients stopped treatment after 3, 4 and 7 weeks, respectively, for various medical reasons (exfoliative dermatitis, legionella pneumonia and other malignancy, respectively). The ORR in the intention-to-treat population was $48 \%(11 / 23)$ including two complete responses and nine partial responses. When excluding the four above-mentioned patients, ORR was $58 \%$ (11/19). Responding patients received a median total lenalidomide dose of $520 \mathrm{mg}$ (range $42-810 \mathrm{mg}$ ), and nonresponders received a median total dose of $177 \mathrm{mg}$ (range $50-650 \mathrm{mg}$ ).

Three patients were excluded from the analysis of progression-free survival, response duration and time to next treatment since after study completion they received either donor lymphocyte infusion (two patients) or allo-SCT (one patient). Median progression-free survival was 6 months (range 0-37+ months) (Supplementary Fig. 1) with five patients having a progression-free survival exceeding 12 months. Median overall survival (OS) was 17 months $(0-65+)$ (Supplementary Fig. 1). All but one of the surviving patients are currently on treatment with ibrutinib or idelalisib.

Median response duration time of the eight responding patients was 12 months (range: 1-29+ months) (Supplementary Fig. 1) and median time to treatment failure (next treatment or death) 18 months (range 3-52+ months).

\section{Toxicity}

The most common grade 3-4 adverse events were hematological: neutropenia (84\%) and thrombocytopenia (55\%). No patient developed anemia $\geq$ grade 3 . The most common non-hematological grade 3-4 adverse events were febrile neutropenia $(n=7)$, pneumonia $(n=5)$, CMV-reactivation $(n=2)$, thrombosis $(n=2)$ and fever of unknown origin $(n=2)$. CMV-reactivation requiring valganciclovir therapy occurred in seven patients $(30 \%)$.

Seven patients (30\%) developed transient TFR (grade III). Six of these responded to treatment, including five partial responses and one complete response. The only patient with TFR who did not respond discontinued treatment early due to legionella pneumonia.

\section{Immune responses}

T cells, NK cells and Natural killer T (NKT) cells were markedly reduced by the combination treatment

After 4 weeks of single-agent lenalidomide treatment, no statistically significant changes were observed in the numbers of $\mathrm{CD}^{+} \mathrm{T}$ cells, $\mathrm{CD} 8^{+} \mathrm{T}$ cells, NK cells and NKT cells. After adding alemtuzumab, all the lymphoid subsets decreased dramatically at week 16 and remained low in most patients at follow-up (weeks 30 and 45) (Fig. 1). The median numbers of $\mathrm{CD} 4^{+}$and $\mathrm{CD} 8^{+} \mathrm{T}$ cells were 157 

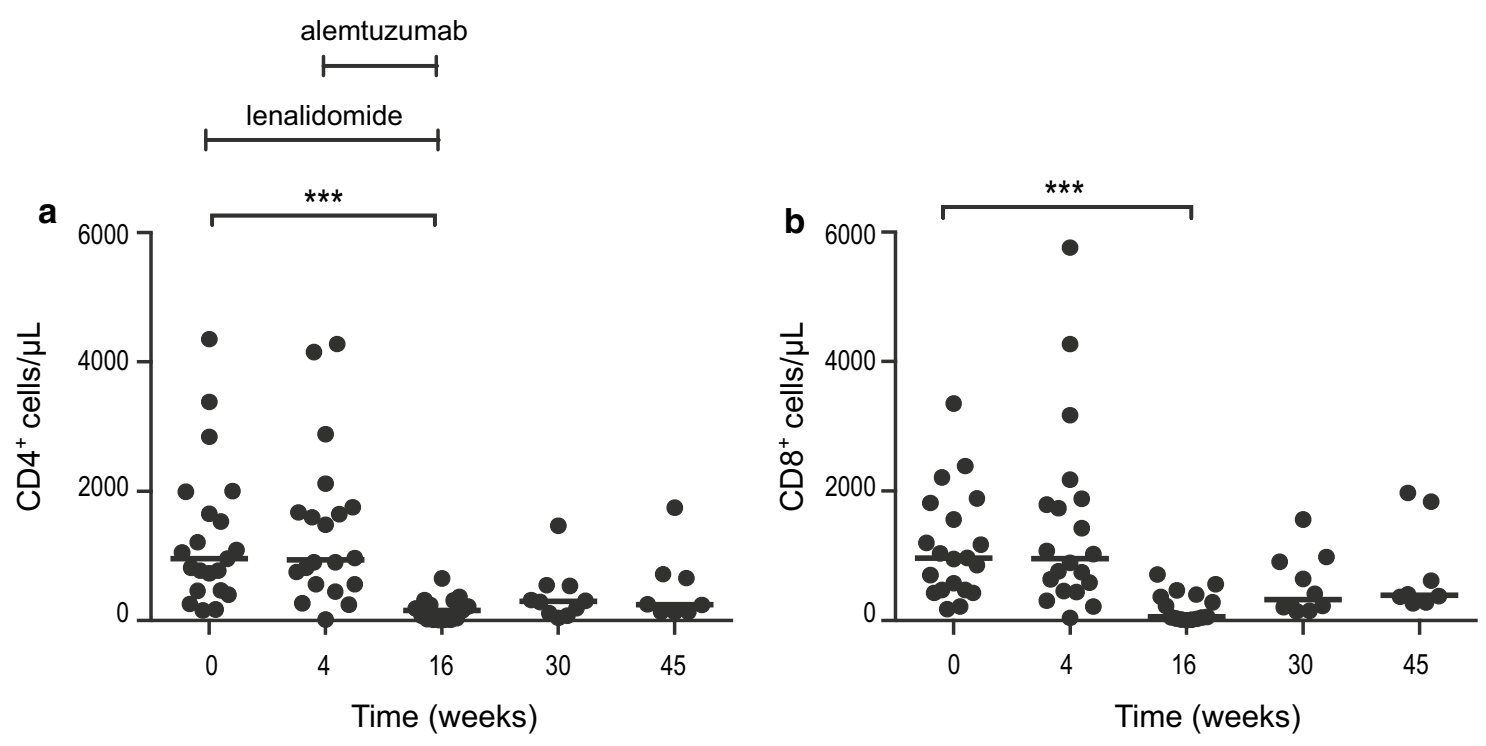

median: $956 \quad 936 \quad 157 \quad 297 \quad 249$
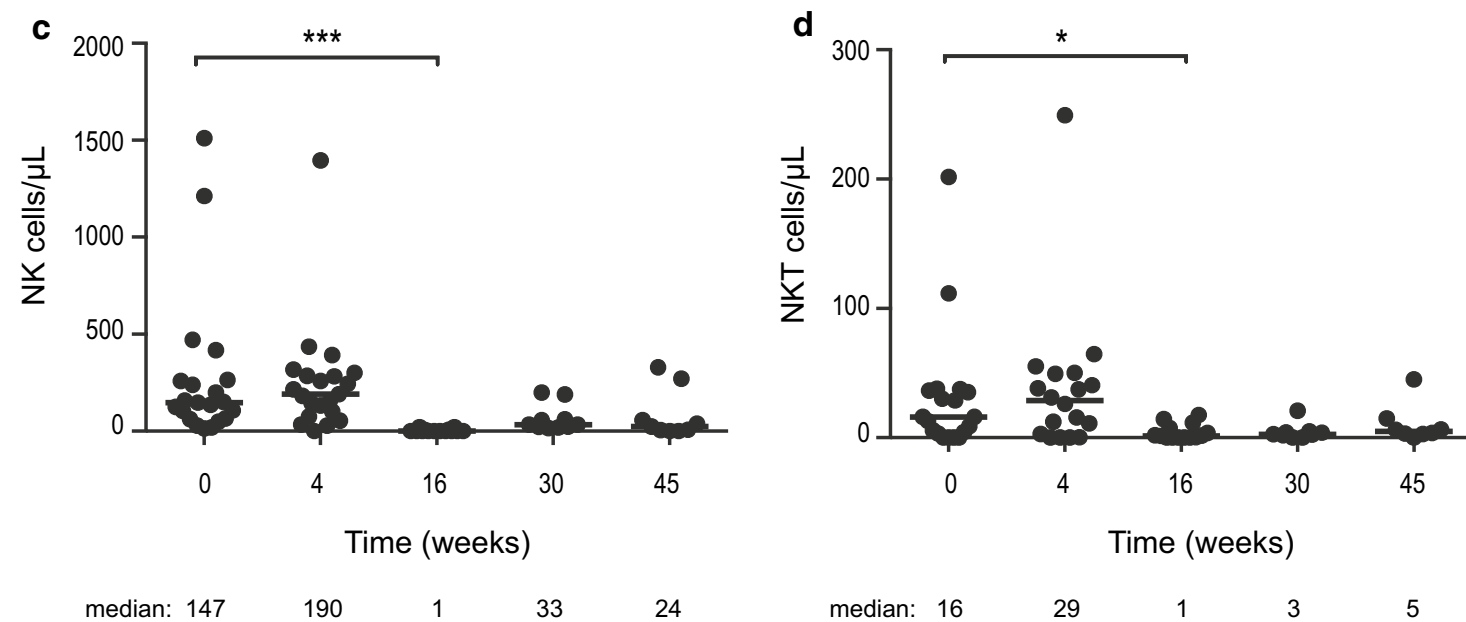

Fig. 1 Absolute numbers of a $\mathrm{CD}^{+}, \mathbf{b ~ C D}^{+}, \mathbf{c} \mathrm{NK}$ and d NKT cells at baseline, during and after therapy. Lenalidomide was administered on weeks 1-16 and alemtuzumab weeks 5-16. Median num-

ber of cells $/ \mu \mathrm{L}$ at each time point is depicted under each figure. $* p<0.05, * * p<0.01, * * * p<0.001$

and 59 cells $/ \mu \mathrm{L}$ at week 16 (end of treatment), 297 and 321 cells $/ \mu \mathrm{L}$ at week 30, and 249 and 392 cells $/ \mu \mathrm{L}$ at week 45 , respectively (Fig. 1a, b).

The proportion of $\mathrm{CD}^{-} \mathrm{T}$ cells increased during treatment. At baseline, the number of $\mathrm{CD}^{2} 2^{-} \mathrm{CD} 3^{+}$cells was low (median 18 cells $/ \mu \mathrm{L}$ ), whereas the number of $\mathrm{CD}_{2}{ }^{+} \mathrm{CD}^{+}$cells was high (median 1828 cells $/ \mu \mathrm{L}$ ). At the end of treatment, the frequency was reversed with $\mathrm{CD} 52^{-}$ cells comprising more than $85 \%$ of all T cells. Also, total CD52 ${ }^{-} \mathrm{T}$ cell numbers increased during treatment (median 292,544 and 343 cells/ $\mu \mathrm{L}$ at weeks 16,30 and 45 , respectively) (data not shown).

\section{Activated $\left(H L A-D R^{+}\right)$and proliferating $\left(K i 67^{+}\right) T$ cells increased during lenalidomide treatment}

After 4 weeks of lenalidomide treatment, no significant increase was observed in the frequency of $\mathrm{Ki}^{+} 7^{+} \mathrm{CD} 4^{+}$ cells (Fig. 2a), while the frequency of $\mathrm{Ki}^{+} 7^{+} \mathrm{CD} 8^{+}$cells increased from 2.3\% (median) (range 0.8-16.9) at baseline to $3.8 \%$ (range $0.8-27.0)$ at week $4(p<0.05)$ (Fig. 2b). At the end of treatment (week 16 ), $\mathrm{Ki}^{+} 7^{+}$cells among both the $\mathrm{CD}^{+}$and $\mathrm{CD}^{+}$subsets had further increased (median 6.2 and $7.0 \%$, respectively, $p<0.006$ and $p<0.05$ ) (Fig. 2a, b), and then, normalization gradually occurred. As 

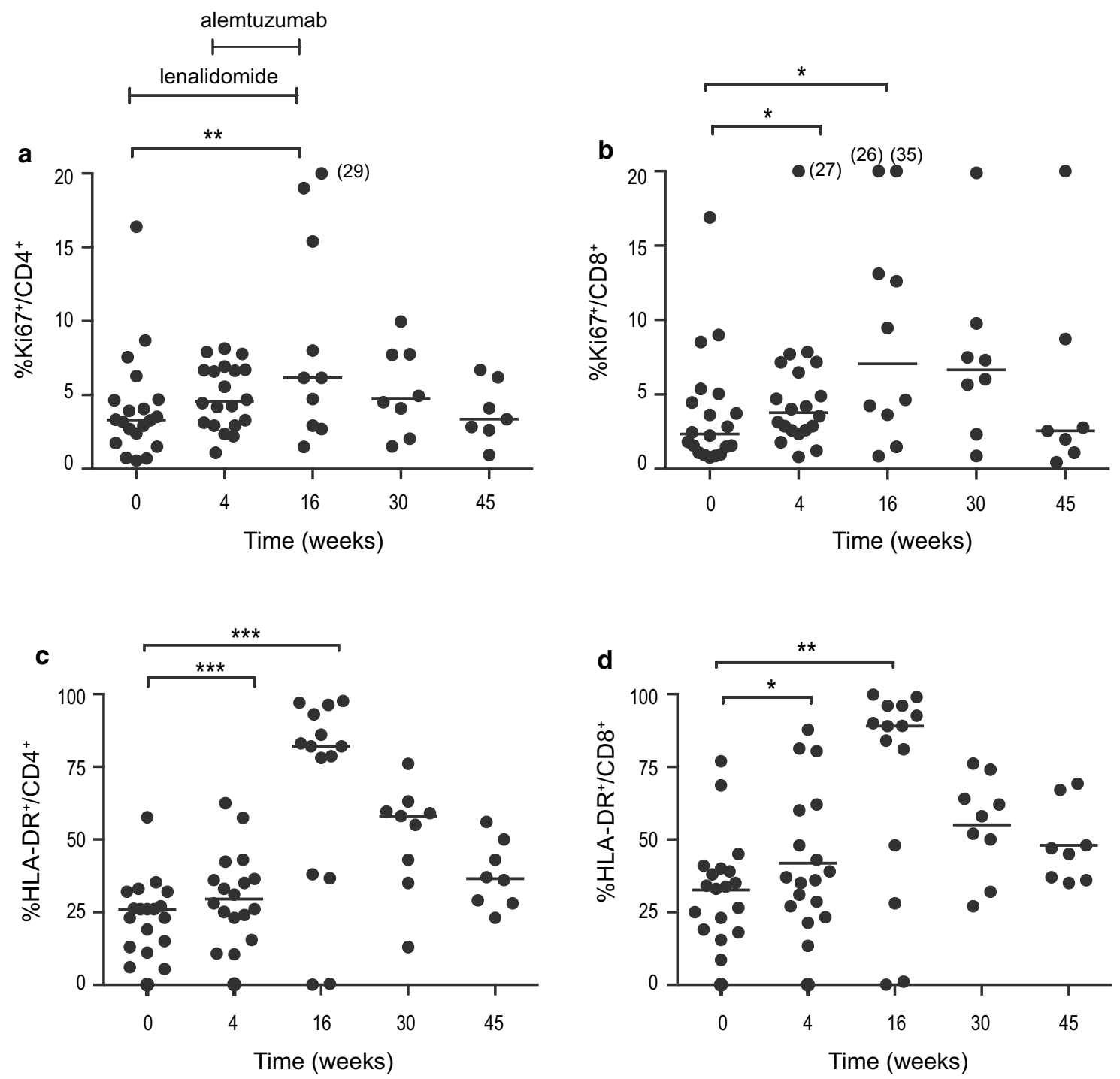

Fig. 2 Percentage of a $\mathrm{Ki} 67^{+} \mathrm{CD} 4^{+}$, b Ki67 ${ }^{+} \mathrm{CD} 8^{+}$, $\mathbf{c ~ H L A - D R}{ }^{+} \mathrm{CD} 4^{+}$and $\mathbf{d} \mathrm{HLA}-\mathrm{DR}^{+} \mathrm{CD} 8^{+}$cells at baseline, during and after therapy. Lenalidomide was administered on weeks $1-16$ and alemtuzumab weeks 5-16. $* p<0.05$, ** $p<0.01, * * * p<0.001$

preliminarily reported earlier [25], a significant increase was observed in the frequency of activated (HLA-DR ${ }^{+}$) $\mathrm{T}$ cells after single-agent lenalidomide treatment. The frequency increased further during the combination therapy, and HLA-DR ${ }^{+}$cells increased from $25 \%$ at baseline to $82 \%$ at week 16 within the $\mathrm{CD}^{+}$subset $(p=0.0009)$ and from 33 to $89 \%$ in the $\mathrm{CD}^{+}$subset $(p=0.0017)$ (Fig. 2c, d). Similar to Ki67 ${ }^{+}$cells, HLA-DR ${ }^{+}$expression gradually normalized during the non-treatment follow-up period. There was no significant change in the proportion of $\mathrm{T}$ cells expressing perforin/granzyme $\mathrm{B}$ during treatment with lenalidomide alone. The combination treatment significantly increased the proportion of granzyme $\mathrm{B}^{+}$cells within $\mathrm{CD}^{+}(p<0.05)$ as well as $\mathrm{CD} 8^{+} \mathrm{T}$ cells $(p<0.05)$ from baseline until week 30 of follow-up (data not shown).
A shift toward a type 2 Thelper (Th2) cells profile and reduced frequency of Th17 and $T_{\text {regs }}$ were observed during combination therapy

$\mathrm{T}$ helper subpopulations were defined by CCR6 and CXCR3 expression as Th1 $\left(\mathrm{CCR}^{-} / \mathrm{CXCR}^{+}\right)$, Th2 $\left(\mathrm{CCR}^{-}{ }^{-} \mathrm{CXCR}^{-}\right)$and $\mathrm{Th} 17\left(\mathrm{CCR}^{+} / \mathrm{CXCR}^{-}\right)$cells. $\mathrm{T}_{\text {regs }}$ were defined as $\mathrm{CD} 4^{+}, \mathrm{CD} 25^{\text {high }}$ and $\mathrm{FOXp}^{+}$. The Th1/Th2 balance (Fig. 3) was unaffected by lenalidomide therapy alone (weeks 1-4), but then the frequency of Th1 cells decreased from 50\% (median) (range 7-81\%) at baseline to $6 \%$ (range 0-79\%) at week 16 (not significant) (Fig. 3a). The proportion of Th2 cells increased from $32 \%$ (median) (10-82\%) at baseline to 88\% (8-99\%) at the end of the combination therapy $(p<0.05)$. The proportion of 

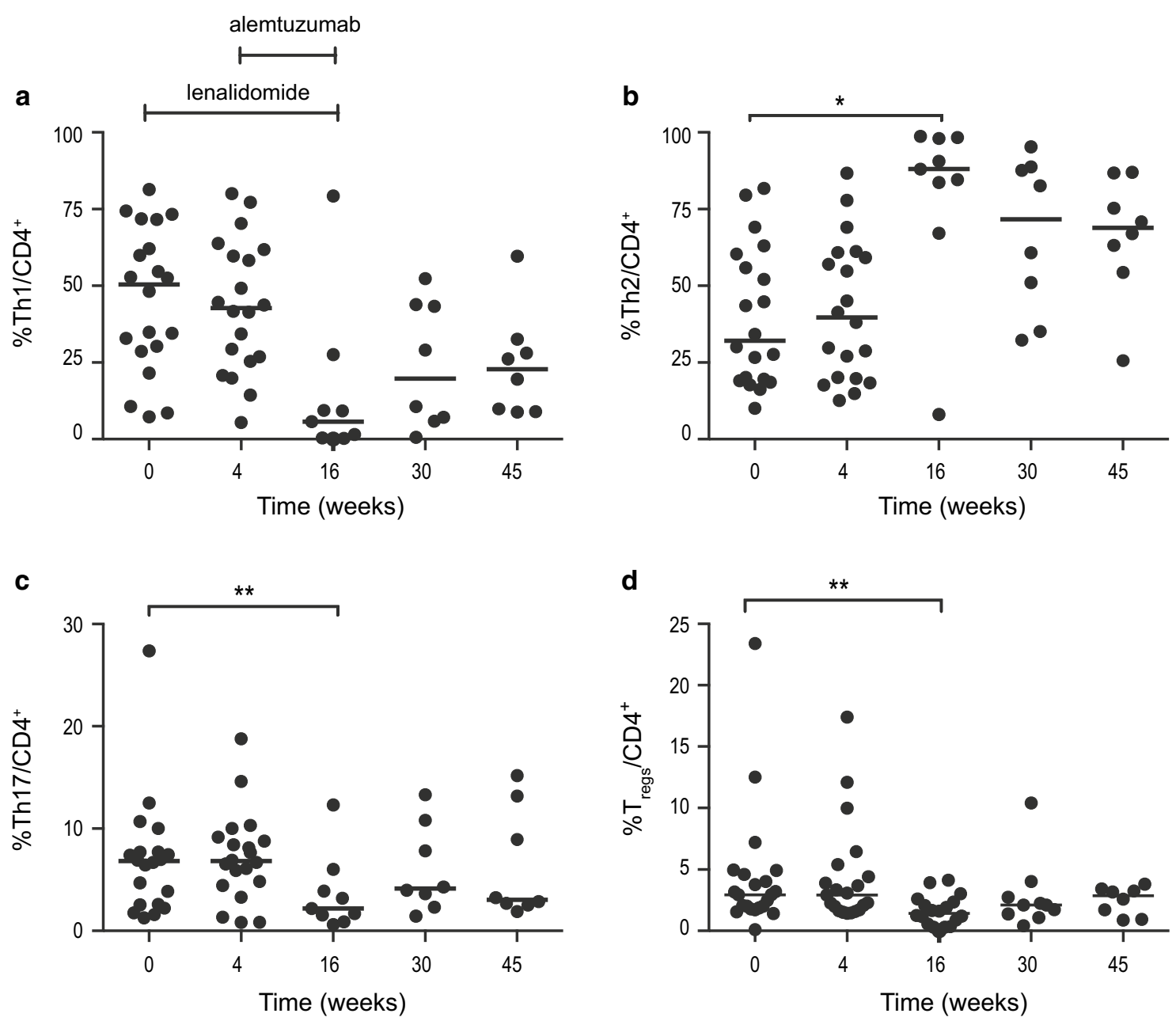

Fig. 3 Percentage of a Th1, b Th2, $\mathbf{c}$ Th17 and $\mathbf{d} \mathrm{T}_{\text {reg }}$ cells at baseline, during and after therapy. Lenalidomide was administered on weeks $1-16$ and alemtuzumab weeks 5-16. $* p<0.05, * * p<0.01, * * * p<0.001$

Th2 cells remained high during follow-up (Fig. 3b). The median percentage of Th17 cells decreased significantly during combination therapy from $7 \%$ at baseline to $2.2 \%$ at week $16(p=0.004)$ (Fig. 3c). The decrease in $T_{\text {regs }}$ observed in part I of the study [25] was confirmed in the present extended analysis ( $p=0.003$ ) (Fig. 3d).

\section{A shift in memory $T$ cell subsets was observed} during therapy

$\mathrm{CD}^{+}$and $\mathrm{CD}^{+}$memory cell subsets were identified by CCR7 and CD45RA expression. The percentages of naïve $\left(\mathrm{CD}^{2} 5 \mathrm{RA}^{+} / \mathrm{CCR} 7^{+}\right)$, central memory $\left(\mathrm{CD}^{2} 5 \mathrm{RA}^{-} /\right.$ $\left.\mathrm{CCR} 7^{+}\right)$, effector memory $\left(\mathrm{CD} 45 \mathrm{RA}^{-} / \mathrm{CCR} 7^{-}\right)$and effector $\left(\mathrm{CD} 45 \mathrm{RA}^{+} / \mathrm{CCR}^{-}\right)$cells were determined. The results for effector memory cells are shown in Fig. 4a and b. After 4 weeks of lenalidomide treatment, the percentage of effector memory $\mathrm{CD}^{+}$cells increased $(p<0.003)$ (Fig. $\left.4 \mathrm{~b}\right)$, while the percentage of effector cells $\left(\mathrm{CD}^{+}{ }^{+}\right.$and $\left.\mathrm{CD} 8^{+}\right)$ decreased $(p<0.01$ and $p<0.0001)$ (Fig. 4c, d). At the end of the combination treatment (week 16), the percentages of naïve $\mathrm{CD} 4^{+}$and $\mathrm{CD} 8^{+} \mathrm{T}$ cells decreased $(p<0.05)$ (Fig. 4e, f). The percentage of effector memory cells increased significantly within both $\mathrm{CD} 4^{+}$and $\mathrm{CD} 8^{+}$cells $(p<0.01)$ (Fig. 4a, b). Central memory T cells appeared to be less affected (Fig. 4g, h).

\section{PD-1 expression remained unaffected by treatment}

The percentage of PD- $1^{+}$cells before treatment was $53 \%$ (median) in the $\mathrm{CD}^{+}$cells and $15 \%$ (median) in the $\mathrm{CD} 8^{+}$ cells. The proportion of PD-1-expressing cells remained unchanged in both $\mathrm{CD}^{+}$(Fig. 5a) and $\mathrm{CD}^{+}$(Fig. 5b) $\mathrm{T}$ cells during lenalidomide, combination therapy and follow-up. No expression of PD-L1 was detected on freshly isolated CLL cells at study start or during therapy. Neither was CTLA-4 surface expression on $\mathrm{T}$ cells observed at study inclusion nor throughout therapy. 

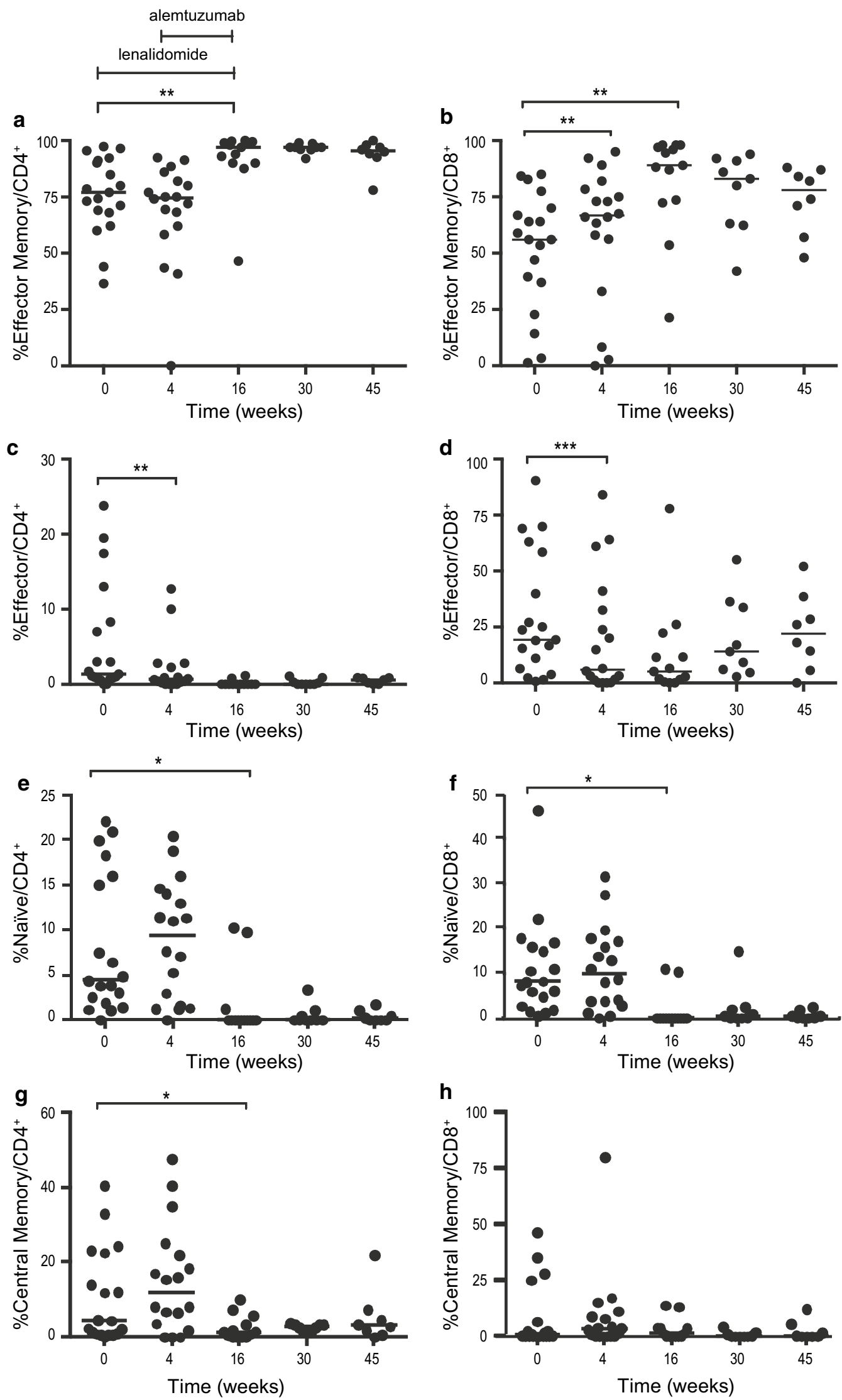
4Fig. 4 Percentage of $\mathrm{T}$ cell subpopulations a effector memory $\mathrm{CD}^{+}$, b effector memory $\mathrm{CD}^{+}$, $\mathbf{c}$ effector $\mathrm{CD} 4^{+}, \mathbf{d}$ effector $\mathrm{CD} 8^{+}$, e naïve $\mathrm{CD} 4^{+}$, f naïve $\mathrm{CD}^{+}, \mathbf{g}$ central memory $\mathrm{CD} 4^{+}, \mathbf{h}$ central memory $\mathrm{CD}^{+}$at baseline, during and after therapy. Lenalidomide was administered on weeks $1-16$ and alemtuzumab weeks $5-16$. $* p<0.05$, ** $p<0.01, * * * p<0.001$

\section{Discussion}

Until recently, patients with high-risk CLL [refractory/ relapsed or with del(17p)/TP53 mutation] had a very poor prognosis $[27,28]$. New drugs, such as ibrutinib, venetoclax and idelalisib, which were not available for CLL patients at the initiation of this study, are now changing the landscape of CLL treatment proving to be highly effective in relapsed or refractory patients even with high-risk cytogenetics [29-32]. Despite the impressive clinical results obtained by, e.g., ibrutinib, patients with del(17p)/TP53 mutation, still relapse and have a relatively short OS [33, 34]. Patients who relapse after treatment with the new drugs or do not tolerate them may still need the previous generation of anti-CLL agents such as alemtuzumab (currently available through a free access program) or other active agents such as lenalidomide.

Lenalidomide as a single agent has shown to be active in CLL [5-7]. It is explored as maintenance therapy for CLL in an ongoing phase III trial and in combination with other agents in phase II studies [35-40].

We report here the final results of a phase I-II trial exploring safety and clinical efficacy of lenalidomide in combination with alemtuzumab in advanced-stage CLL, with a focus on the effects of the two drugs on $\mathrm{T}$ cell subsets.

As for part I of the study [25], the present full study report confirmed an acceptable safety profile of the combination. However, grade 3-4 infections appeared to be more frequent than that reported in previous studies in which each drug was used separately [6, 23, 24]. The incidence of symptomatic CMV-reactivation $(30 \%)$ was similar to that reported with alemtuzumab alone. Thus, the immuneenhancing potential of lenalidomide seemed not to translate into a reduced risk of infections. Higher doses of lenalidomide might have been more effective, but dose escalation was hindered by the low MTD of only $5 \mathrm{mg} /$ day. Notably, grade 3-4 neutropenia occurred in more than $80 \%$ of patients, despite the use of G-CSF prophylaxis. This is in contrast to most previous studies reporting a tolerated dose of $10 \mathrm{mg}[8,41]$, even though one study noted that lenalidomide in heavily pretreated patients was feasible only at a dose of $5 \mathrm{mg}$ [42]. Despite the low dose of lenalidomide, ORR of our drug combination appeared to be clinically meaningful. More than half of our elderly poor-prognosis patients with advanced-stage CLL responded and those who tolerated therapy reached a reasonably long response duration time. However, the results of the present study should be interpreted with caution as the number of patients was low.

Effects of lenalidomide indicated that immune stimulatory effects on T cells started early in spite of the low dose of lenalidomide. Not only activation (HLA-DR expression) was observed, but also an increased proportion of $\mathrm{Ki} 67^{+} \mathrm{CD} 8^{+} \mathrm{T}$ cells at week 4 . This was accompanied by a relative increase in $\mathrm{CD}^{+}$effector memory cells and a decrease in $\mathrm{CD}^{+}$effector cells, indicating an increase in antigen-experienced $\left(\mathrm{CD} 45 \mathrm{RA}^{-}\right) \mathrm{CD}^{+}$cells which is in line with what have been observed in multiple myeloma patients [43, 44].

A limitation of our study is the marked T cell-depleting effect of alemtuzumab, which complicated the analysis of total $\mathrm{T}$ cell subsets. We therefore focused on the relative changes within major subsets, as the functions of remaining $\mathrm{T}$ cells in blood after alemtuzumab therapy are likely to be of importance for the immune status of the patients. As described previously [45], most post-treatment $\mathrm{T}$ cells were $\mathrm{CD}_{2}{ }^{-}$. The total $\mathrm{CD} 4^{+} \mathrm{T}$ cell numbers at the end of the combination treatment are slightly higher in the current study than after treatment with alemtuzumab alone [23].

At week 16, i.e., at the end of treatment, an increase in the percentage of Th2 cells was noted accompanied by a decrease in $\mathrm{T}_{\text {reg }}$, Th17 and naïve $\mathrm{T}$ cells. This is in contrast to previous results, suggesting that lenalidomide could cause a shift from Th2 to Th1 cells [17]. Our observations are most likely attributed to alemtuzumab therapy, similar to the relative increase in Th2 cells during alemtuzumab treatment seen in patients with multiple sclerosis [46]. Furthermore, an increase in the proportion of granzyme $\mathrm{B}^{+} \mathrm{T}$ cells was noted, implying an enhanced cytotoxic potential.

PD-1 binds through its ligands on immune cells and target cells countering TCR-induced T cell proliferation, cytotoxicity and cytokine production [18]. Studies in CLL have suggested that lenalidomide might affect the expression of the PD-1/PD-L1 receptors $[15,20]$. However, we were not able to confirm those findings, which is in line with a study in multiple myeloma patients where no difference in the frequency of $\mathrm{CD} 8^{+} \mathrm{PD} 1^{+}$cells could be noted comparing untreated and lenalidomide-treated patients [43].

Moreover, we did not find PD-L1 expression on CLL cells, which is in contrast to previous studies [15, 19]. However, preliminary results from a phase II study applying PD-1 blockade in relapsed/refractory CLL, including patients with Richter's transformation, showed promising clinical activity on the transformed cells, but not against the untransformed CLL clone [47], which might support the absence of PD-L1 on the CLL clone. 

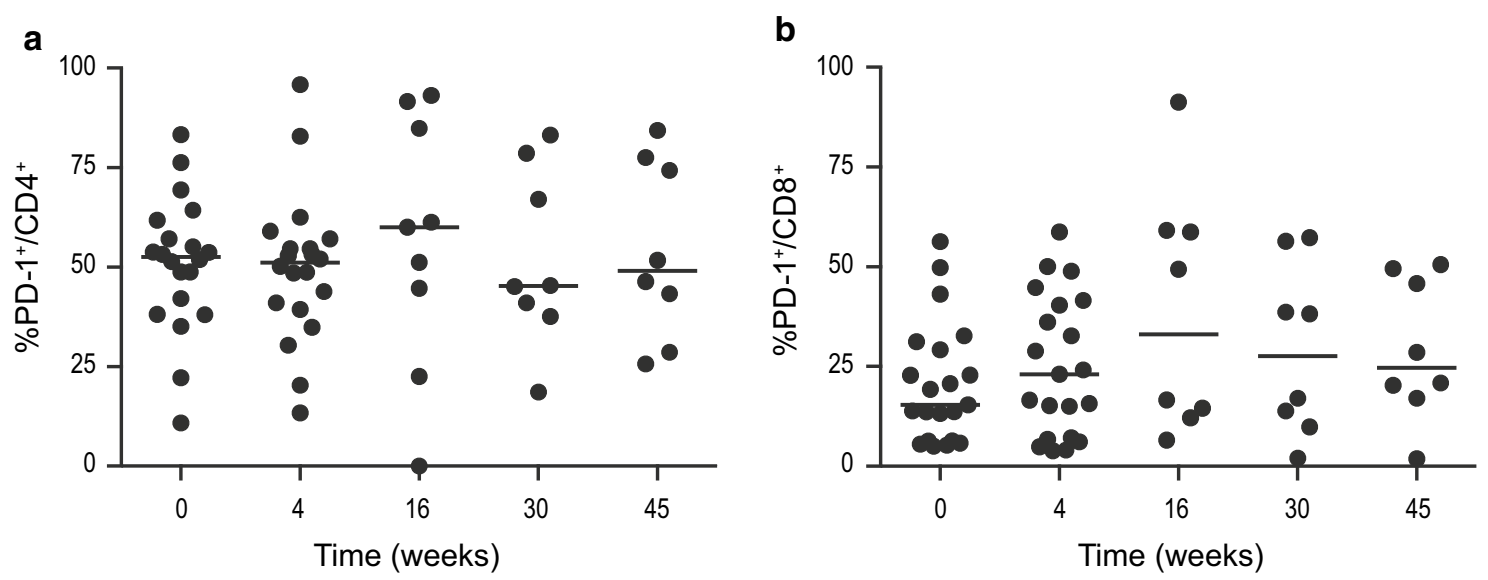

Fig. 5 Percentage of a PD $-1^{+} \mathrm{CD} 4^{+}$and $\mathbf{b} \mathrm{PD}-1^{+} \mathrm{CD} 8^{+}$cells at baseline, during and after therapy. Lenalidomide was administered weeks on $1-16$ and alemtuzumab weeks $5-16$. $* p<0.05, * * p<0.01$, *** $p<0.001$

In conclusion, our study showed that lenalidomide alone or in combination with alemtuzumab induced various immunomodulatory effects on T cells in CLL patients. Further studies on lenalidomide as an immune-enhancing agent in CLL and other disorders are warranted.

Acknowledgements Special thanks to Maria B Larsson, Dept of Clinical Pathology/Cytology, Division of Hematopathology, Flow Cytometric laboratory, Karolinska University Hospital and to Elisabeth Rilegård, Clinical Trial Unit, Dept of Hematology, Karolinska University Hospital. We also thank Ms Leila Relander for secretarial assistance.

Author contributions MW analyzed the data and performed the statistical analysis. FM performed laboratory experiments. MP and SES analyzed the data. AÖ and JL designed the study, treated patients and analyzed the data. All authors interpreted the data, wrote and approved the manuscript.

Funding The study was supported by the Karolinska Institutet Foundations, Stockholm County Council, the Swedish Cancer Society, the Cancer and Allergy Foundation, the Cancer Society in Stockholm, AFA Insurance and Celgene Inc.

\section{Compliance with ethical standards}

Conflict of interest A Österborg is a member of the Data Monitoring Committee on lenalidomide phase III trials in CLL. A. Österborg, H. Mellstedt, J. Lundin and L. Hansson have received unrestricted scientific grants from Celgene Inc. The other authors declare no conflict of interest.

Open Access This article is distributed under the terms of the Creative Commons Attribution 4.0 International License (http://creativecommons.org/licenses/by/4.0/), which permits unrestricted use, distribution, and reproduction in any medium, provided you give appropriate credit to the original author(s) and the source, provide a link to the Creative Commons license, and indicate if changes were made.

\section{References}

1. Ramsay AG, Johnson AJ, Lee AM et al (2008) Chronic lymphocytic leukemia $\mathrm{T}$ cells show impaired immunological synapse formation that can be reversed with an immunomodulating drug. J Clin Invest 118:2427-2437. doi:10.1172/JCI35017

2. Riches JC, Davies JK, McClanahan F et al (2013) T cells from CLL patients exhibit features of T-cell exhaustion but retain capacity for cytokine production. Blood 121:1612-1621. doi:10.1182/blood-2012-09-457531

3. Mellstedt H, Choudhury A (2006) T and B cells in B-chronic lymphocytic leukaemia: Faust, Mephistopheles and the pact with the Devil. Cancer Immunol Immunother 55:210-220. doi:10.1007/s00262-005-0675-4

4. Palma M, Gentilcore G, Heimersson K et al (2016) T cells in chronic lymphocytic leukemia display dysregulated expression of immune checkpoints and activation markers. Haematologica (in press)

5. Bühler A, Wendtner CM, Kipps TJ et al (2016) Lenalidomide treatment and prognostic markers in relapsed or refractory chronic lymphocytic leukemia: data from the prospective, multicenter phase-II CLL-009 trial. Blood Cancer J 6:e404. doi:10.1038/bcj.2016.9

6. Chanan-Khan A, Miller KC, Musial L et al (2006) Clinical efficacy of lenalidomide in patients with relapsed or refractory chronic lymphocytic leukemia: results of a phase II study. J Clin Oncol 24:5343-5349. doi:10.1200/JCO.2005.05.0401

7. Ferrajoli A, Lee BN, Schlette EJ et al (2008) Lenalidomide induces complete and partial remissions in patients with relapsed and refractory chronic lymphocytic leukemia. Blood 111:52915297. doi:10.1182/blood-2007-12-130120

8. Maffei R, Colaci E, Fiorcari S et al (2016) Lenalidomide in chronic lymphocytic leukemia: the present and future in the era of tyrosine kinase inhibitors. Crit Rev Oncol Hematol 97:291302. doi:10.1016/j.critrevonc.2015.09.003

9. Giannopoulos K, Schmitt M, Wlasiuk P et al (2008) The high frequency of $\mathrm{T}$ regulatory cells in patients with B-cell chronic lymphocytic leukemia is diminished through treatment with thalidomide. Leukemia 22:222-224. doi:10.1038/sj.leu.2404869

10. Idler I, Giannopoulos K, Zenz T et al (2010) Lenalidomide treatment of chronic lymphocytic leukaemia patients reduces 
regulatory T cells and induces Th17 T helper cells. Br J Haematol 148:948-950. doi:10.1111/j.1365-2141.2009.08014.x

11. D'Arena G, Rossi G, Minervini MM et al (2011) Circulating regulatory $\mathrm{T}$ cells in "clinical" monoclonal B-cell lymphocytosis. Int J Immunopathol Pharmacol 24:915-923

12. Acebes-Huerta A, Huergo-Zapico L, Gonzalez-Rodriguez AP et al (2014) Lenalidomide induces immunomodulation in chronic lymphocytic leukemia and enhances antitumor immune responses mediated by NK and CD4 T cells. Biomed Res Int. doi:10.1155/2014/265840

13. Haslett PA, Corral LG, Albert M et al (1998) Thalidomide costimulates primary human $\mathrm{T}$ lymphocytes, preferentially inducing proliferation, cytokine production, and cytotoxic responses in the CD8+ subset. J Exp Med 187:1885-1892

14. LeBlanc R, Hideshima T, Catley LP et al (2004) Immunomodulatory drug costimulates T cells via the B7-CD28 pathway. Blood 103:1787-1790. doi:10.1182/blood-2003-02-0361

15. Ramsay AG, Clear AJ, Fatah R et al (2012) Multiple inhibitory ligands induce impaired T-cell immunologic synapse function in chronic lymphocytic leukemia that can be blocked with lenalidomide: establishing a reversible immune evasion mechanism in human cancer. Blood 120:1412-1421. doi:10.1182/ blood-2012-02-411678

16. Lee BN, Gao H, Cohen EN et al (2011) Treatment with lenalidomide modulates T-cell immunophenotype and cytokine production in patients with chronic lymphocytic leukemia. Cancer 117:3999-4008. doi:10.1002/cncr.25983

17. Dredge K, Marriott JB, Todryk SM et al (2002) Protective antitumor immunity induced by a costimulatory thalidomide analog in conjunction with whole tumor cell vaccination is mediated by increased Th1-type immunity. J Immunol 168:4914-4919

18. Keir ME, Butte MJ, Freeman GJ et al (2008) PD-1 and its ligands in tolerance and immunity. Annu Rev Immunol 26:677704. doi:10.1146/annurev.immunol.26.021607.090331

19. Brusa D, Serra S, Coscia $M$ et al (2013) The PD-1/PD-L1 axis contributes to T-cell dysfunction in chronic lymphocytic leukemia. Haematologica 98:953-963. doi:10.3324/ haematol.2012.077537

20. Gassner FJ, Zaborsky N, Neureiter D et al (2014) Chemotherapy-induced augmentation of $\mathrm{T}$ cells expressing inhibitory receptors is reversed by treatment with lenalidomide in chronic lymphocytic leukemia. Haematologica 99:67-69. doi:10.3324/ haematol.2013.098459

21. Walker LS, Sansom DM (2011) The emerging role of CTLA4 as a cell-extrinsic regulator of $\mathrm{T}$ cell responses. Nat Rev Immunol 11:852-863. doi:10.1038/nri3108

22. Motta M, Rassenti L, Shelvin BJ et al (2005) Increased expression of CD152 (CTLA-4) by normal T lymphocytes in untreated patients with B-cell chronic lymphocytic leukemia. Leukemia 19:1788-1793. doi:10.1038/sj.leu.2403907

23. Keating MJ, Flinn I, Jain V et al (2002) Therapeutic role of alemtuzumab (Campath-1H) in patients who have failed fludarabine: results of a large international study. Blood 99:3554-3561

24. Osterborg A, Dyer MJ, Bunjes D et al (1997) Phase II multicenter study of human CD52 antibody in previously treated chronic lymphocytic leukemia. European Study Group of CAMPATH-1H Treatment in Chronic Lymphocytic Leukemia. J Clin Oncol 15:1567-1574

25. Sylvan SE, Rossmann E, Mozaffari F et al (2012) Phase I study of lenalidomide and alemtuzumab in refractory chronic lymphocytic leukaemia: maintaining immune functions during therapy-induced immunosuppression. Br J Haematol 159:608-612. doi:10.1111/bjh.12077

26. Hallek M, Cheson BD, Catovsky D et al (2008) Guidelines for the diagnosis and treatment of chronic lymphocytic leukemia: a report from the International Workshop on Chronic Lymphocytic
Leukemia updating the National Cancer Institute-Working Group 1996 guidelines. Blood 111:5446-5456. doi:10.1182/ blood-2007-06-093906

27. Tam CS, O'Brien S, Lerner S et al (2007) The natural history of fludarabine-refractory chronic lymphocytic leukemia patients who fail alemtuzumab or have bulky lymphadenopathy. Leuk Lymphoma 48:1931-1939. doi:10.1080/10428190701573257

28. Zenz T, Mohr J, Edelmann J et al (2009) Treatment resistance in chronic lymphocytic leukemia: the role of the p53 pathway. Leuk Lymphoma 50:510-513. doi:10.1080/10428190902763533

29. Byrd JC, Brown JR, O'Brien S et al (2014) Ibrutinib versus ofatumumab in previously treated chronic lymphoid leukemia. $\mathrm{N}$ Engl J Med 371:213-223. doi:10.1056/NEJMoa1400376

30. Furman RR, Sharman JP, Coutre SE et al (2014) Idelalisib and rituximab in relapsed chronic lymphocytic leukemia. N Engl J Med 370:997-1007. doi:10.1056/NEJMoa1315226

31. Osterborg A, Udvardy M, Zaritskey A et al (2016) Phase III, randomized study of ofatumumab versus physicians' choice of therapy and standard versus extended-length ofatumumab in patients with bulky fludarabine-refractory chronic lymphocytic leukemia. Leuk Lymphoma 57:2037-2046. doi:10.3109/10428194.2015.11 22783

32. Roberts AW, Davids MS, Pagel JM et al (2016) Targeting BCL2 with Venetoclax in Relapsed Chronic Lymphocytic Leukemia. N Engl J Med 374:311-322. doi:10.1056/NEJMoa1513257

33. Byrd JC, Furman RR, Coutre SE et al (2015) Three-year followup of treatment-naive and previously treated patients with CLL and SLL receiving single-agent ibrutinib. Blood 125:2497-2506. doi:10.1182/blood-2014-10-606038

34. Winquist M, Asklid A, Andersson PO et al (2016) Real-world results of ibrutinib in patients with relapsed or refractory chronic lymphocytic leukemia: data from 95 consecutive patients treated in a compassionate use program. Haematologica. doi:10.3324/ haematol.2016.144576

35. Badoux XC, Keating MJ, Wen S et al (2013) Phase II study of lenalidomide and rituximab as salvage therapy for patients with relapsed or refractory chronic lymphocytic leukemia. J Clin Oncol 31:584-591. doi:10.1200/JCO.2012.42.8623

36. Chanan-Khan A, Zaritskey A, Egyed M (2014) Phase 3 study of oral lenalidomide as maintenance therapy for patients with B-cell chronic lymphocytic leukemia (CLL). ASCO Annual Meeting. J Clin Oncol, 32Suppl; abstract TPS7125 [Abstract], Chigaco, IL, USA

37. Chavez JC, Piris-Villaespesa M, Dalia S et al (2016) Results of a phase II study of lenalidomide and rituximab for refractory/ relapsed chronic lymphocytic leukemia. Leuk Res 47:78-83. doi:10.1016/j.leukres.2016.05.012

38. James DF, Werner L, Brown JR et al (2014) Lenalidomide and rituximab for the initial treatment of patients with chronic lymphocytic leukemia: a multicenter clinical-translational study from the chronic lymphocytic leukemia research consortium. J Clin Oncol 32:2067-2073. doi:10.1200/JCO.2013.51.5890

39. Maurer C, Pflug N, Bahlo J et al (2016) Bendamustine and rituximab in combination with lenalidomide in patients with chronic lymphocytic leukemia. Eur J Haematol 97:253-260. doi:10.1111/ejh.12714

40. Vitale C, Falchi L, Ten Hacken E et al (2016) Ofatumumab and lenalidomide for patients with relapsed or refractory chronic lymphocytic leukemia: correlation between responses and immune characteristics. Clin Cancer Res 22:2359-2367. doi:10.1158/1078-0432.CCR-15-2476

41. Wendtner CM, Hallek M, Fraser GA et al (2016) Safety and efficacy of different lenalidomide starting doses in patients with relapsed or refractory chronic lymphocytic leukemia: results of an international multicenter double-blinded randomized phase II trial. Leuk Lymphoma 57:1291-1299. doi:10.3109/10428194.20 15.1128540 
42. Maddocks K, Ruppert AS, Browning R et al (2014) A dose escalation feasibility study of lenalidomide for treatment of symptomatic, relapsed chronic lymphocytic leukemia. Leuk Res 38:1025-1029. doi:10.1016/j.leukres.2014.05.011

43. Busch A, Zeh D, Janzen V et al (2014) Treatment with lenalidomide induces immunoactivating and counter-regulatory immunosuppressive changes in myeloma patients. Clin Exp Immunol 177:439-453. doi:10.1111/cei.12343

44. Neuber B, Herth I, Tolliver C et al (2011) Lenalidomide enhances antigen-specific activity and decreases CD45RA expression of $\mathrm{T}$ cells from patients with multiple myeloma. $\mathrm{J}$ Immunol 187:1047-1056. doi:10.4049/jimmunol.1002460

45. Lundin J, Porwit-MacDonald A, Rossmann ED et al (2004) Cellular immune reconstitution after subcutaneous alemtuzumab
(anti-CD52 monoclonal antibody, CAMPATH-1H) treatment as first-line therapy for B-cell chronic lymphocytic leukaemia. Leukemia 18:484-490. doi:10.1038/sj.leu.2403258

46. Zhang X, Tao Y, Chopra M et al (2013) Differential reconstitution of $\mathrm{T}$ cell subsets following immunodepleting treatment with alemtuzumab (anti-CD52 monoclonal antibody) in patients with relapsing-remitting multiple sclerosis. J Immunol 191:58675874. doi:10.4049/jimmunol.1301926

47. Ding W, Dong H, Call TG (2015) PD-1 Blockade with Pembrolizumab (MK-3475) in relapsed/refractory CLL including Richter transformation: an early efficacy report from a phase 2 trial (MC1485). 57th American Society of Hematology (ASH), 126:23 \#834 [Abstract], Orlando, FL, USA 